\title{
The Impact of Environmental Factors on Outcome in Residential Programs
}

Francine Cournos, M.D.

Altbough community residential placements are among the leading areas of program expansion for the chronic mentally ill, they bave been designed without scientifically validated models. The autbor reviews the literature on the impact of residential environment on the course of serious mental illness. In most studies, environmental variables were better predictors of outcome than were patient variables. This overall finding suggests the value of further research on environment and the importance of applying the results to program development.

Residential placements are one of the leading areas of program expansion in the care of the chronic mentally ill. In New York State, for example, at a time when only limited funds were available for new mental health initiatives, the number of community residence beds increased from 308 in 1978 to 4,520 in 1986, one of the largest new investments of mental health dollars (1). Large numbers of patients now leave long-term hospital care for another structured living setting. In fiscal year 1984, of the

Dr. Cournos is director of the Washington Heights Community Service of the New York State Psychiatric Institute and assistant clinical professor of psychiatry at Columbia University College of Physicians and Surgeons. Address correspondence to her at the New York State Psychiatric Institute, 722 West 168th Street, New York, New York 10032.
12,561 discharges from New York State mental hospitals, 45 percent returned to living with their families, 15 percent lived alone, and 30 percent moved into another institutional or residential treatment setting (2).

The same social and economic forces that led to deinstitutionalization (3) also resulted in the development of residential programs for the chronic mentally ill. Because the development of residential programs was not a response to a scientifically based demonstration of their efficacy, we have no well-established models that tell us which types of patients flourish in which residential settings. In an attempt to increase understanding of the principles that can be extracted from existing studies, this paper will review our current state of knowledge about the impact of residential environment on outcome in chronic mental illness.

\section{Family environments}

The largest number of studies focusing on the impact of residential environment on outcome in chronic mental illness are those that examine the effect of the family environment on the course of schizophrenia. Because to varying degrees residential care simulates and substitutes for the biological family, the same types of relationships may operate in residential settings.

Much of the literature has focused on the expressed emotionprimarily the criticism and overinvolvement-of family members. Early studies and their later replications and extensions have demonstrated better general outcome and lower relapse rates for schizo- phrenic patients who live in households with low expressed emotion (4-8).

It is not clear, however, whether the level of expressed emotion reflects the character of the patient who elicits this response or the character of the family who offers it. There is substantial evidence that interventions that reduce expressed emotion in the household are associated with better outcome. It appears that the social environment created by the interaction between the patient and his relatives can be altered in a way that is responsive to the perceptual, cognitive, and emotional vulnerabilities caused by schizophrenia, and that such alterations can improve the outlook for the patient. It is plausible that successful family intervention programs not only address dysfunctional family patterns and offer models for understanding and managing schizophrenia but actually teach people how to effectively treat a schizophrenic relative in ways that would be maladaptive and unnatural for other family relationships.

We do not yet know whether these research findings apply to other types of chronic mental illness and other types of living arrangements, but assessments of expressed emotion in residential settings would be an interesting area for future exploration. If studies show that the family findings are applicable to residential programs, the results could provide staff with a better idea of how to avoid the criticism and overprotection that appear to be associated with poor outcome.

Findings about the family management of schizophrenia are consistent with the larger body of 
knowledge that has established several important principles about successful environments for the chronic mentally ill. There is substantial evidence that settings that overly protect and control patients are harmful to the functioning of their residents. This finding has been well documented in a variety of institutions (9-11). Such factors as procedures that cater to staff convenience, lack of flexible responses to individual needs, and physical isolation from normal community life have been associated with significant social disability and regression.

On the other hand, environments that offer little protection from demands that exceed the patient's capabilities often lead to symptom exacerbation and relapse $(12,13)$. This problem seems to be related to vulnerabilities present in schizophrenia, and undoubtedly in other psychotic illnesses, in such areas as information processing and regulation of arousal.

In effect, the patient is in a precarious position between two dangers: the danger of relapse from being faced with too many demands and the danger of regression from being faced with too few (14). Even when an optimal environment has been created, probably no dilemma is more common for families and residential staff alike than deciding when it is safe to push someone with a schizophrenic illness and when it is preferable to back off and settle for a lesser goal.

\section{Development of \\ residential programs}

Residential programs for the chronic mentally ill are an important alternative to family care. While many patients do extremely well at home, there are good reasons to consider other options. The patient and family may want to separate from each other, just as adult children and their parents normally do in our society. $\mathrm{Pa}$ tients and families may be unable to live together successfully, despite professional help. Family caretakers age and thus lose their capacity to provide care. For these

Hospital and Community Psychiatry and other reasons, residential placement may be an appealing alternative.

How have the principles of community care for the chronic mentally ill influenced residential treatment programs? To examine this question, it is necessary to review the recent history of these programs.

Foster family care programs for the mentally ill are the oldest form of alternative care, and by 1940 about 900 patients were living in these homes in the U.S. (15). In the 1950s a few programs were set up as work farms on which patients lived and worked to maintain the farm (16). The 1960s saw a growing number of patients in alternative settings, although the number of such placements controlled by mental health professionals was small (17).

Within the traditional system in the 1960s were halfway houses that were envisioned as transitional programs leading to independent living (18). Fairweather Lodges were model programs in which patients lived together and supported themselves by creating and managing an independent business (19).

The 1960s also saw what might be termed an antipsychiatry movement, typified by Soteria House $(20,21)$. Here psychosis was handled as a psychological growth experience, and medical care was avoided. All these movements, however, were very small. The overwhelming majority of group settings were totally outside the mental health system. They included skilled nursing facilities, healthrelated facilities, adult homes, and board-and-care homes.

Segal and Aviram's thorough and moving account (17) of sheltered care in California in the 1970 s noted that 82 percent of the more than 12,000 chronic mentally ill people living in community care settings were in board-andcare homes in which they received meals and nonprofessional supervision. These homes had at best a tenuous connection with the mental health system. Although 88 percent of the residents were on medication, when trouble arose a psychiatrist's help was sought only 15 percent of the time. In spite of the many publicized deficiencies of these settings, many clients were satisfied. This does not mean, of course, that these homes were optimal, or even satisfactory, places to live. But they offered opportunities for independence and initiative that had not been present in mental hospitals.

In effect, most mental patients considered residential care an improvement over life in the hospital, but they were living in settings removed from psychiatric care. This situation led to an open discussion of the inadequacies of the system of community care for the chronic mentally ill. The 1980 s have seen the expansion of a spectrum of alternative living programs within the mental health system itself. Until recently most new beds were managed by health departments or departments of social services. But now many beds are opened and managed by departments of mental health. This sponsorship allows the development of residential programs specifically geared to the needs of the mentally ill and permits improved links to mental health treatment.

\section{Evaluation of residential program environments}

Now that we have control over an increasing number of community residential placements, and a growing awareness of the importance of environment on the course of chronic mental illness, it is important to examine these programs to determine the most successful approaches. Should community residences be conceptualized as treatment programs or living settings? Should staff be professionals or laymen? How much supervision should they provide? How close a connection with the mental health system should programs have? What types of activities, social relationships, and physical characteristics are most likely to produce good outcome? Will patients be able to transfer skills learned in these settings to independent living? These would all be appropriate subjects for research. 
Many of the early reports on residential care were descriptive (16) and focused on halfway houses, where only a small percentage of patients in community placements actually resided (17). The characteristics of patients with good outcome in these programs varied widely, suggesting that either the patient populations were not comparable or that patient characteristics accounted for only a limited amount of the variance in outcome.

A small number of recent studies have begun to look at the environment in an attempt to understand its contribution to outcome. Segal and others (22) and Coulton and associates $(23,24)$ have used Moos' Community-Oriented Programs Environment Scale (COPES) (25) to examine how residents and operators of community homes perceive their environments. This instrument examines important environmental characteristics in three areas. The Personal Relationships subscale focuses on such factors as the degree of support, resident involvement, and encouragement of spontaneity and expression of feeling. The Treatment Programs subscale looks at encouragement of autonomy, the degree of focus on personal problems, and the expression of anger and aggression. The third subscale, System Maintenance, rates the amount of order and organization, program clarity, and methods of control.

Segal and associates (22) studied 499 residents and 234 home operators, looking at whether agreement between the residents and operators on the nature of the home environment would predict good outcome, as defined by internal and external social integration. As it turned out, agreement between staff and clients was only weakly correlated with improved outcome. The best predictors of good outcome were the perceptions of the residents themselves. Those who were satisfied with the home and experienced it as a stable and self-contained facility that was not treatment oriented had the best social integration.
Coulton and associates $(23,24)$ looked at the match between patients and their environments to examine the degree to which the patients' needs, capacities, and aspirations were consistent with the resources, demands, and opportunities of the community care home. An exploratory study of 51 patients successfully discharged from state hospitals to 40 community care homes suggested that good outcome, defined as the home's ability to maintain or improve the patient's level of functioning at the time of hospital discharge, was correlated with the patient's perception that the home was a good match for his needs. As with the Segal study, the perceptions of staff are only weakly predictive of outcome.

Taken together, these studies suggest that patients who feel satisfied and perceive a good fit between their needs and the home environment may make a better adjustment.

Several studies have compared the influence of environmental variables and patient variables on outcome. Linn and others (26) looked at the outcome of 210 men who had been placed in 150 different foster homes. Approximately 75 percent of the men were schizophrenic. At four months, patients in foster care showed improved social functioning and better overall adjustment in comparison to a matched group of hospitalized controls.

Further follow-up by these investigators revealed that patient characteristics did not significantly predict social adjustment in the home (27). However, patient satisfaction was correlated with good outcome. Also, certain characteristics of the home were significant. An average of two patients in the home, a smaller total number of occupants, and the presence of children in the home were significantly correlated with good outcome. Conversely, more than two patients in the home and a larger total number of occupants were associated with poor outcome.

Schizophrenic patients did worse if there was more activity in the home, more sponsor supervision, or more intense follow-up by a social worker. These same characteristics were correlated with improvement in nonschizophrenic patients. This study supports the beneficial effects of a nonhospital environment and suggests that the characteristics of the homes and the patient's subjective satisfaction with his environment correlate more strongly with good outcome than do patient variables.

Kruzich and Kruzich (28) reached similar conclusions in their study of 87 patients discharged from state hospitals to one of three types of settings: skilled nursing facilities, intermediate care facilities, and congregate care facilities. Good outcome, defined as social integration within the facility, correlated with a moderate rigidity of routine, a moderate amount of skills programming, less nursing supervision, and a closer social connection between staff and residents. The five most important facility variables accounted for 40 percent of the variation in internal integration. The inclusion of psychosocial functioning, the most powerful patient variable and the only statistically significant one, increased the ability to predict social integration by only 8 percent.

In one of the most interesting studies in this area, Hull and Thompson $(29,30)$ looked at the outcome for 296 predominately middle-aged schizophrenic patients living in 157 board-and-care homes in Canada. These were small facilities with a mean of 2.7 patients per home. The researchers applied Wolfensberger's concept (31) of "normalization," developed for the care of the mentally retarded, to a mentally ill population. Wolfensberger defined normalization as "the utilization of means which are as culturally normative as possible, in order to establish and/or maintain personal behaviors and characteristics which are as culturally normative as possible."

The Hull and Thompson study examined the home environment using a 172-item instrument based 
on a modification of the Program Analysis of Service Systems (PASS), which is essentially an operational definition of normalization. The PASS covers many of the same variables as the COPES but focuses less on subjective experience and more on the adaptive skills of the residents and the physical characteristics of the settings. Twenty patient variables were assessed, including demographics, diagnosis, hospitalization history, and physical and verbal abusiveness. The outcome measure was instrumental role performance, a complex measure based on 150 items that assessed social functioning and ability to maintain self-care and use community resources.

Hull and Thompson found that board-and-care homes achieve the best results when they are centrally located in a community, treat residents with dignity and respect, provide opportunities for autonomy and initiative, avoid overprotecting residents with unnecessary rules and restrictions, offer activities promoting social integration, and ensure residents' culturally normative appearance and behavior. Individual variables accounted for 3 percent of the variance, and environmental variables accounted for 57 percent of the variance.

All three studies that compared the contribution of residential environment and patients' characteristics to outcome found that environment was the more powerful predictor. Although these studies may have failed to identify patient characteristics that might have more powerful predictive value, the role of environment seems impressive.

\section{Conclusions}

There is a growing body of evidence to suggest that the course of serious mental illness can be favorably modified by providing a lowstress environment that neither overwhelms nor understimulates the patient. Studies of families caring for a schizophrenic patient demonstrate that reducing the levels of expressed emotion diminishes the chance of relapse and improves overall adjustment (4-8).
Work by Segal and Coulton and their associates (22-24) shows that patients who experience a residential setting as satisfactory have better outcome, even when their view of the setting is different from that of the staff. Perhaps feeling satisfied is a sign of low stress, and low stress results in better functioning.

Linn and associates' foster home study $(26,27)$ demonstrates that increased sponsor activity and a higher level of professional supervision are associated with poor outcome for patients with schizophrenia. This finding was similar to the finding of a day hospital study carried out by the same investigators (32) and is consistent with the view that intense social interaction may exceed the patient's tolerance. Kruzich and Kruzich (28) discovered that a path between highdemand and low-demand environments was associated with the best outcome, as evidenced by increased social functioning in settings with moderate structure and programming.

Hull and Thompson $(29,30)$ took the model of normalization that had been developed for a mentally retarded population and used it to examine settings for the mentally ill. The most successful homes avoided the pitfalls of traditional institutional care, in part by establishing environments that reproduced important aspects of a household low in expressed emotion. Perhaps some of the same principles are applicable for the mentally ill and the mentally retarded alike. Both populations have problems in processing information and responding to highly demanding situations, yet both need enough stimulation and opportunities for learning to achieve minimum functioning.

Taken together, these findings suggest that supportive and satisfying social relationships, in conjunction with moderate expectations for functioning, correlate with the best outcome and that excessive structure, protection, and supervision have the opposite effect.

Although we have made significant gains in our knowledge, we still have more questions than an- swers. We are far from having optimal models for residential settings tailored to the needs of specific patients. With the current push to expand residential programs, the pursuit of research in this area becomes all the more urgent.

One promising area would be studying expressed emotion in residential settings. Another would be expanding the work of Hull and Thompson, with its careful focus on environment and behavioral outcome, to determine the degree of applicability of normalization concepts to residential programs for the mentally ill.

For the entire range of residential options available to discharged patients, including family management and independent living, we need to be able to identify those environmental variables that promote good outcome for specific patient groups. Where possible, studies of patients randomly assigned to different residential settings would contribute significantly to our understanding of the impact of program design. Finally, we need models that simultaneously ensure the provision of treatment while creating an atmosphere that feels like home.

\section{References}

1. Community residence bed development (graph). Albany, Bureau of Residential Services, New York State Office of Mental Health, 1986

2. Report, Bureau of Statistical Analysis. Albany, Office of Planning and Program Evaluation, New York State Office of Mental Health, 1985

3. Lerman P: Deinstitutionalization: A Cross-Problem Analysis. Rockville, Md, National Institute on Alcohol Abuse and Alcoholism, 1981

4. Brown GW, Birley JLT, Wing JK: Influence of family life on the course of schizophrenic disorders: a replication. British Journal of Psychiatry 121:241258, 1972

5. Vaughn CE, Leff JP: The influence of family and social factors on the course of psychiatric illness. British Journal of Psychiatry 129:125-137, 1976

6. Falloon IRH, Boyd JL, McGill CW, et al: Family management in the prevention of exacerbations of schizophrenia. New England Journal of Medicine 306:1437-1440, 1982

7. Leff J, Kuipers L, Berkowitz R, et al: A controlled trial of social intervention in 
the families of schizophrenic patients: two year follow-up. British Journal of Psychiatry 146:594-600, 1985

8. Hogarty GE, Anderson CM, Reiss DJ, et al: Family psychoeducation, social skills training, and maintenance chemotherapy in the aftercare treatment of schizophrenia. Archives of General Psychiatry 43:633-642, 1986

9. Stanton AH, Schwartz MS: The Mental Hospital. New York, Basic Books, 1954

10. Goffman E: Asylums. New York, Doubleday, 1961

11. Gruenberg EM: The social breakdown syndrome: some origins. American Journal of Psychiatry 123:1483-1489, 1967

12. Liberman HP, Evans CC: Behavioral rehabilitation for chronic mental patients. Journal of Clinical Psychopharmacology 5(suppl): 8S-14S, 1985

13. Anderson CM, Reiss DJ, Hogarty GE: Schizophrenia in the family: a practitioner's guide to psychoeducation and management. New York, Guilford, 1986

14. Lamb HR: Treating the Long-Term Mentally Ill. San Francisco, JosseyBass, 1982

15. Caton CLM: Management of Chronic Schizophrenia. New York, Oxford University Press, 1984

16. Carpenter MD: Residential placement for the chronic psychiatric patient: a review and evaluation of the literature. Schizophrenia Bulletin 4:384-398,
1978

17. Segal SP, Aviram U: The Mentally III in Community-Based Sheltered Care: A Study of Community and Social Integration. New York, Wiley, 1978

18. Budson RD: The Psychiatric Halfway House. Pittsburgh, University of Pittsburgh Press, 1978

19. Fairweather GW, Sanders DH, Maynard $\mathrm{H}$, et al: Community Life for the Mentally Ill: An Alternative to Institutional Care. Chicago, Aldine, 1969

20. Mosher LR, Menn A, Matthews SM Soteria: evaluation of a home-based treatment for schizophrenia. American Journal of Orthopsychiatry 45:455467, 1975

21. Wilson HS: Deinstitutionalized Residential Care for the Mentally Disordered. New York, Grune \& Stratton, 1982

22. Segal SP, Everett-Dille L, Moyles EW: Congruent perceptions in the evaluation of community-care facilities. Journal of Community Psychology 7:6068, 1979

23. Coulton CJ, Holland TP, Fitch V: Person-environment congruence and psychiatric patient outcome in community-care homes. Administration in Mental Health 12:71-88, 1984

24. Coulton CJ, Fitch V, Holland TP: A typology of social environments in community care homes. Hospital and Community Psychiatry 36:373-377, 1985

25. Moos R, Otto J: The Community-Ori- ented Programs Environment Scale: a methodology for the facilitation and evaluation of social change. Community Mental Health Journal 8:28-37, 1972

26. Linn MW, Caffey EM, Klett CJ, et al: Hospital vs community (foster) care for psychiatric patients. Archives of General Psychiatry 34:78-83, 1977

27. Linn MW, Klett CJ, Caffey EM: Foster home characteristics and psychiatric patient outcome. Archives of General Psychiatry 37:129-132, 1980

28. Kruzich JM, Kruzich SJ: Milieu factors influencing patients' integration into community residential facilities. Hospital and Community Psychiatry 36:378-382, 1985

29. Hull JT, Thompson JC: Factors which contribute to normalization in residential facilities for the mentally ill. Community Mental Health Journal 17:107113,1981

30. Hull JT, Thompson JC: Predicting adaptive functioning among mentally ill persons in community settings. American Journal of Community Psychology 9:247-268, 1981

31. Wolfensberger W: The Principle of Normalization in Human Services. Toronto, National Institute on Mental Retardation, 1972

32. Linn MW, Caffey EM, Klett CJ: Day treatment and psychotropic drugs in the aftercare of schizophrenic patients. Archives of General Psychiatry 36:1055-1066, 1979

\section{Beyond Model Programs: Evaluation of a Countywide System of Residential Treatment Programs}

Marjorie Wherley, M.S.W. Sandra Bisgaard, M.P.H.

Assessing deinstitutionalization as a social policy requires examining a system of programs ratber than single, "model" services. The autbors report an evaluation of 19 residential treatment programs in Hennepin County, Minnesota, that provide three different levels of care (intensive, transitional, and supportive) for mentally ill clients. Data on cli- ent characteristics, program outcomes, and bospitalization costs were collected in two study periods between 1980 and 1985. The results showed that the programs served three distinct client subpopulations that differed in recidivism, vocational status, discharge setting, and costs according to the type of program. Clients in all programs made substantial gains in community integration, and as a group the programs were cost-effective.
Since its beginning, deinstitutionalization has been one of this country's most controversial social policies, and after two decades the debate is far from resolved. The most enduring and frequently asked questions continue to be the most basic ones: Does deinstitutionalization work as a large-scale social policy? How can it be evaluated as a social policy?

One answer is to analyze the behavior and demographic characteristics of mentally ill individuals 